\title{
Erratum to: Production of carotenoids by microalgae: achievements and challenges
}

\author{
João C. Varela ${ }^{1} \cdot$ Hugo Pereira ${ }^{1,2} \cdot$ Marta Vila $^{2} \cdot$ Rosa León $^{2}$
}

Published online: 4 August 2015

(C) Springer Science+Business Media Dordrecht 2015

\section{Erratum to: Photosynth Res}

\section{DOI 10.1007/s11120-015-0149-2}

Some pathways were shown incorrectly in Fig. 3 in the original publication. The correct figure is shown below.

The online version of the original article can be found under doi:10.1007/s11120-015-0149-2.

Rosa León

rleon@uhu.es

1 Centre of Marine Science, University of Algarve, Campus de Gambelas, Faro, Portugal

2 Laboratory of Biochemistry and Molecular Biology,

University of Huelva, Marine International Campus of

Excellence (CEIMAR), Huelva, Spain 
Fig. 3 Carotenoid biosynthesis pathway in chlorophytes. GGPP, geranylgeranyl pyrophosphate; PSY, phytoene synthase; PDS, phytoene desaturase; Z-ISO, $\zeta$-carotene isomerase; ZDS, $\zeta$-carotene desaturase; CRTISO, carotene isomerase; LCYE, lycopene $\varepsilon$ cyclase; LCYB, lycopene $\beta$ cyclase; CYP97C3, cytochrome P450 \&-hydroxylase; CYP97A5, cytochrome $\mathrm{P} 450 \beta$ -

hydroxylase; $\mathrm{CHYB}$, carotene $\beta$-hydroxylase; BKT, $\beta$ carotene oxygenase; ZEP, zeaxanthin epoxidase; VDE, violaxanthin de-epoxidase

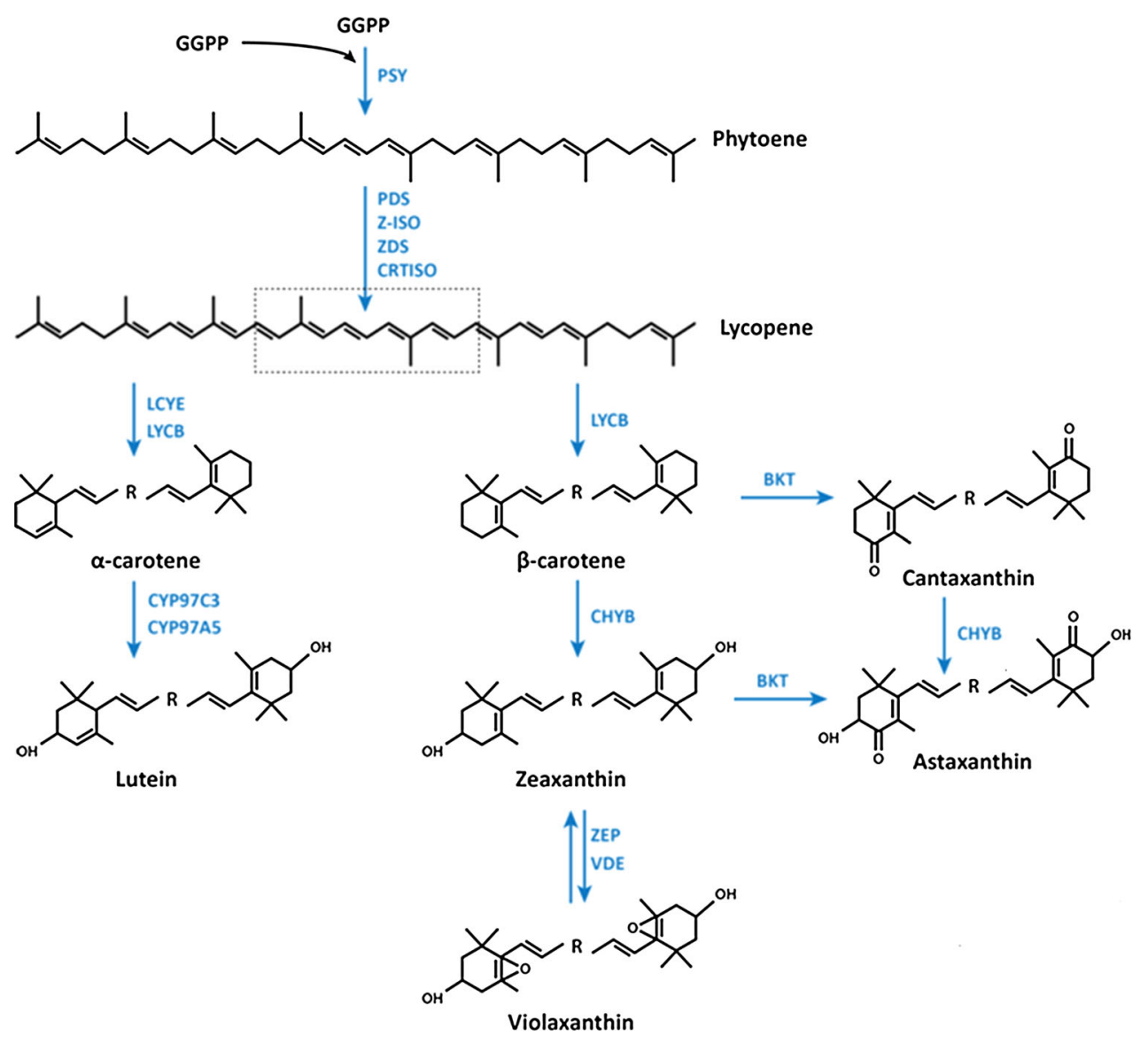

